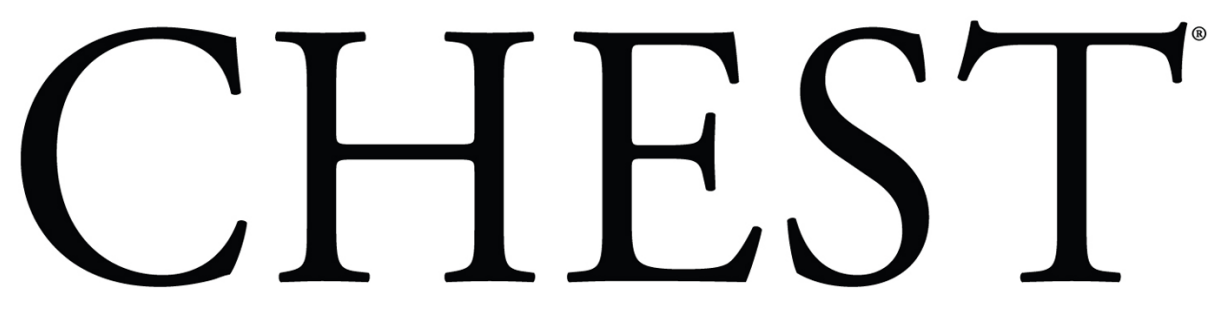

Official publication of the American C ollege of Chest Physicians

\title{
Toxicology in the Critical Care Unit
}

Philip M. Alapat and Janice L. Zimmerman

Chest 2008;133;1006-1013

DOI 10.1378/chest.07-1840

The online version of this article, along with updated information and services can be found online on the World Wide Web at: http://chestjournal.org/cgi/content/abstract/133/4/1006

CHEST is the official journal of the American College of Chest Physicians. It has been published monthly since 1935. Copyright 2007 by the American College of Chest Physicians, 3300 Dundee Road, Northbrook IL 60062. All rights reserved. No part of this article or PDF may be reproduced or distributed without the prior written permission of the copyright holder

(http://www.chestjournal.org/misc/reprints.shtml). ISSN: 0012-3692.

A M E R I C A N C O L L E G E O F

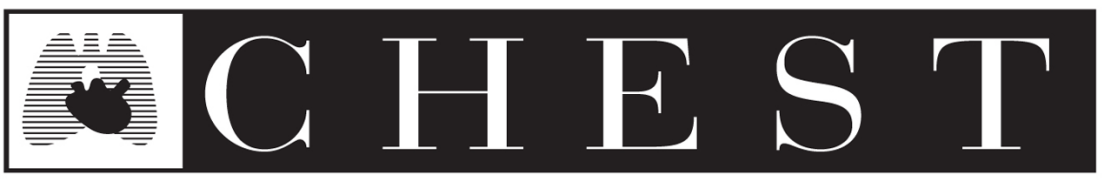
$\begin{array}{llllllllll}\mathrm{P} & \mathrm{H} & \mathrm{Y} & \mathrm{S} & \mathrm{I} & \mathrm{C} & \mathrm{I} & \mathrm{A} & \mathrm{N} & \mathrm{S}\end{array}$ 


\title{
Toxicology in the Critical Care Unit ${ }^{\star}$
}

\author{
Philip M. Alapat, MD; and Janice L. Zimmerman, MD, FCCP
}

\begin{abstract}
Toxicologic conditions are encountered in critically ill patients due to intentional or unintentional misuse of or exposure to therapeutic or illicit drugs. Additionally, toxicities related to medical interventions may develop in hospitalized patients. This review focuses on recent developments in the field of critical care toxicology. Early interventions to decrease absorption or enhance elimination of toxins have limited value. Specific interventions to manage toxicities due to analgesics, sedative-hypnotics, antidepressants, antipsychotics, cardiovascular agents, alcohols, carbon monoxide, and cholinergic agents are reviewed. Hospital-acquired toxicities due to methemoglobinemia, propylene glycol, and propofol should be recognized and treated. The clinician is continually required to incorporate clinical judgment along with available scientific data and clinical evidence to determine the best therapy for toxicologic conditions.
\end{abstract}

(CHEST 2008; 133:1006-1013)

Key words: alcohols; analgesics; antidepressants; antipsychotics; carbon monoxide; methemoglobinemia; overdose; propofol

Abbreviations: $\mathrm{CA}=$ cyclic antidepressant; $\mathrm{CCB}=$ calcium-channel blocker; $\mathrm{KCC}=$ King's College criteria; NAC $=N$-acetylcysteine; NMS $=$ neuroleptic malignant syndrome; SDAC $=$ single-dose activated charcoal; $\mathrm{SS}=$ serotonin syndrome; SSRI = selective serotonin reuptake inhibitor

$\mathbf{T}$ oxicologic conditions in patients admitted to the ICU usually result from intentional or unintentional misuse of or exposure to therapeutic or illicit drugs. Additionally, significant toxicities can develop in hospitalized patients being treated for other illnesses. While evidence-based management is ideal, the characteristics of this patient population limit the feasibility of high-quality interventional trials. Recommendations for care of these patients are usually based on pharmacologic knowledge, animal studies, human volunteer studies, case reports, and consensus opinions. This review focuses on relevant updates on toxicities commonly encountered in adult critical care medicine. More exhaustive information can be found in reviews. ${ }^{1-4}$

${ }^{\star}$ From The Methodist Hospital (Dr. Zimmerman) and Baylor College of Medicine (Dr. Alapat), Houston, TX.

The authors have no personal or financial conflicts of interest associated with this article.

Manuscript received July 25, 2007; revision accepted November 16, 2007.

Reproduction of this article is prohibited without written permission from the American College of Chest Physicians (www.chestjournal. org/misc/reprints.shtml).

Correspondence to: Janice L. Zimmerman, MD, FCCP, 6550 Fannin, Suite 1001, Houston, TX 77030; e-mail: janicez@tmhs.org

DOI: 10.1378/chest.07-1840

\section{EARLy MANAGEMENT Issues}

Critical care management of the patient with a toxicologic condition requires rapid diagnosis and appropriate specific treatment while providing supportive care. Diagnosis requires a thorough history and physical examination combined with several laboratory tests. ${ }^{3}$ The clinical evaluation may reveal the presence of characteristic clinical syndromes, called toxidromes, that suggest particular offending agents. However, many overdose patients treated in the ICU have used more than one agent, and toxidromes may overlap. Laboratory tests that may be of value include calculation of the anion, osmolal, and oxygen saturation gap, ECG, and quantitative toxicology assays for specific drugs. If the specific agent is unclear or multiple drugs have been ingested, an acetaminophen level should be obtained because of the lack of specific signs or symptoms and the potential benefit afforded by early, appropriate therapy. Quantitative testing for other drugs or toxins should be guided by clinical and laboratory findings. Qualitative toxicology assays performed on urine detect a limited number of drugs and have little impact on patient management.5,6 
Several interventions have been routinely performed in patients with suspected oral overdose to decrease GI absorption or enhance elimination with little evidence of effectiveness (Table 1). Of these interventions, single-dose activated charcoal (SDAC) is the most utilized. The benefit of SDAC decreases when comparing administration at 60 to $120 \mathrm{~min}$ after ingestion in volunteer studies with a singleagent ingestion. ${ }^{7}$ There is a theoretical benefit to administering charcoal at later times if there is a suspicion of delayed GI absorption.

\section{ANALGESICS}

Analgesics are the most common agents that result in toxicity necessitating hospitalization throughout the world. Acetaminophen (paracetamol) accounts for the majority of toxicity and accounts for the highest number of deaths from poisoning in the United States. ${ }^{16}$ The utility of $\mathrm{N}$-acetylcysteine (NAC) as an antidote in preventing acetaminophen-induced hepatotoxicity has been demonstrated since 1977. The Rumack-Matthew nomogram uses acetaminophen levels to determine the need for NAC administration in single acute ingestions of immediate-release acetaminophen., ${ }^{47}$ Unfortunately, many patients have a history of long-term use, repeated ingestions, or use of extended-release formulations that limit the utility of the nomogram. ${ }^{18} \mathrm{In}$

Table 1-Interventions To Limit Absorption or Enhance Elimination of Toxins

\begin{tabular}{|c|c|}
\hline Interventions & Recommendations \\
\hline Cathartics & Not recommended; no clinical benefit ${ }^{8}$ \\
\hline Ipecac & Not recommended; no clinical benefit ${ }^{9} \rightleftharpoons$ \\
\hline Gastric lavage & 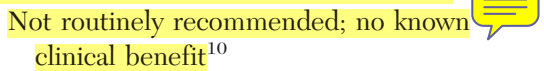 \\
\hline $\begin{array}{l}\text { Whole-bowel } \\
\text { irrigation }\end{array}$ & $\begin{array}{l}\text { Not recommended for routine use; may be } \\
\text { of benefit in ingestions of sustained- } \\
\text { release or enteric-coated drugs }{ }^{11}\end{array}$ \\
\hline $\begin{array}{l}\text { Urine alkalinization } \\
\qquad(\mathrm{pH}>7.5)\end{array}$ & Recommended in salicylate ingestions ${ }^{12}$ \\
\hline SDAC & $\begin{array}{l}\text { Beneficial if administered within } 1 \mathrm{~h} \text { of } \\
\text { ingestion; benefit beyond } 1 \mathrm{~h} \text { after } \\
\text { ingestion cannot be excluded }\end{array}$ \\
\hline $\begin{array}{l}\text { Multiple-dose } \\
\text { activated } \\
\text { charcoal }\end{array}$ & $\begin{array}{l}\text { Not recommended for routine use; increases } \\
\text { drug elimination of carbamazepine, } \\
\text { dapsone, phenobarbital, quinine, and } \\
\text { theophylline; no known clinical benefit }{ }^{13}\end{array}$ \\
\hline $\begin{array}{l}\text { Renal replacement } \\
\text { therapy }\end{array}$ & $\begin{array}{l}\text { Beneficial in lithium, toxic alcohol, } \\
\text { salicylate, valproate, and theophylline } \\
\text { toxicities; other toxicities may also } \\
\text { benefit, but require patient specific } \\
\text { consideration }{ }^{14} \text {; continuous renal } \\
\text { replacement therapy not recommended } \\
\text { for routine use; however, specific patients } \\
\text { unable to tolerate conventional } \\
\text { hemodialysis may benefit }{ }^{15}\end{array}$ \\
\hline
\end{tabular}
phen, assessment of a second acetaminophen level 4 to $6 \mathrm{~h}$ after the first level is recommended if the initial level was in the nontoxic range. ${ }^{19}$ Regardless of the time after ingestion, therapy with NAC provides significant benefit to those patients with acetaminophen-induced hepatic enzyme elevation. ${ }^{1}$

NAC can be administered orally or IV with equivalent effects ${ }^{18,20}$; Table 2 provides dosing. The IV formulation was approved in the United States in 2004; however, significant experience with compounding an IV formulation from the oral preparation has developed, and the compounded product appears to be safe. ${ }^{21}$ The use of compounded medications is governed by local pharmacy boards; thus, clinicians need to obtain input from pharmacists regarding the legality of using compounded NAC. Either form of NAC should be administered within the first $8 \mathrm{~h}$ after ingestion to prevent hepatotoxicity. ${ }^{22}$ Oral administration of NAC may cause vomiting due to the odor, and higher doses of antiemetics may be necessary. IV administration of NAC is associated with anaphylactoid reactions that are usually easily managed. Another therapeutic consideration when treating a single acute ingestion is the shorter dosing schedule of IV NAC compared to the oral form ( $20 \mathrm{~h}$ vs $72 \mathrm{~h}$ ).

Definitive treatment guidelines are not established for patients who present with chronic or repeated ingestions of acetaminophen. Transaminase elevation $(>50 \mathrm{IU} / \mathrm{L})$ and an acetaminophen level $>10 \mathrm{mg} / \mathrm{L}$ on presentation have been suggested as indications for treating with NAC. ${ }^{24}$ Generally, treatment with $\mathrm{NAC}$, whether oral or IV, is continued in these patients until serum acetaminophen levels are undetectable and liver function has normalized or is normalizing. SDAC may reduce the need for NAC treatment if used within $2 \mathrm{~h}$ of acute acetaminophen ingestion. ${ }^{25}$ A recent review ${ }^{26}$ suggests that the concomitant use of activated charcoal and NAC therapy improves patient outcomes. The oral NAC dose does not need to be increased if administered after activated charcoal, nor does there need to be a time lag between the two therapies. ${ }^{27}$

Table 2-Dosing of IV and Oral NAC Following Toxic Acetaminophen Ingestion*

\begin{tabular}{cc}
\hline \hline \multicolumn{1}{c}{ Dosage } & \multicolumn{1}{c}{ Special Considerations } \\
\hline $\begin{array}{c}\text { Oral: } 140 \mathrm{mg} / \mathrm{kg} \text { loading dose } \\
\text { followed by } 70 \mathrm{mg} / \mathrm{kg} \mathrm{q} 4 \mathrm{~h}\end{array}$ & $\begin{array}{c}\text { Any NAC vomited within } 1 \mathrm{~h} \\
\text { of administration should be } \\
\text { for } 17 \mathrm{doses}\end{array}$ \\
IV: $150 \mathrm{mg} / \mathrm{kg}$ loading dose & Use with caution in asthmatics \\
over $15 \mathrm{~min}$ followed by & and patients in whom an \\
$50 \mathrm{mg} / \mathrm{kg}$ infusion over 4 & anaphylactoid reaction is a \\
h, followed by $100 \mathrm{mg} / \mathrm{kg}$ & concern \\
over $16 \mathrm{~h}$ (total $300 \mathrm{mg} / \mathrm{kg}$ ) & \\
\hline
\end{tabular}

*From Flomenbaum et al. ${ }^{23}$ 
Acetaminophen-induced hepatitis may progress to fulminant hepatic failure, and appropriate referral for liver transplantation may be necessary. The King's College criteria (KCC) for prognosis in acetaminophen-induced hepatoxicity (Table 3) are often used, but other indicators include lactate and amylase levels. ${ }^{28}$ Patients who fit the KCC have a predictably high mortality, but the sensitivity is not ideal; thus, liver transplant may be of benefit to some patients who do not fit the KCC.

Ingestion of opioid analgesics is increasing, and misuse may result in significant respiratory, CNS, or hemodynamic depression. Critical care management of these complications is usually based on providing supportive care. The opioid antagonist naloxone is used to reverse significant respiratory depression associated with opioids. Typically, patients respond to IV doses of 0.04 to $0.4 \mathrm{mg}$; however, synthetic opioids such as fentanyl or buprenorphine may require doses as high as $\geq 10 \mathrm{mg} .{ }^{1,30}$ Counteracting the respiratory depressant effect of longer-acting opioids may require a continuous infusion of naloxone. In these cases, the naloxone infusion is initiated at an hourly rate of two thirds of the IV bolus dose needed to reverse the respiratory depression and titrated to effect. Tramadol, an opioid considered to be a safer alternative to conventional opioids, should be recognized as a drug with abuse potential. Rare but significant toxicity, including death, has been associated with this drug especially when combined with other CNS depressants. ${ }^{31}$ Seizures are a common manifestation of tramadol intoxication and usually occur within $24 \mathrm{~h}$ of ingestion. ${ }^{32}$ The misuse of fentanyl as a street drug that is often combined with heroin is increasingly recognized. Urine toxicology assays will not detect fentanyl as an opiate. ${ }^{33,34}$

\section{Sedative-Hypnotics and Muscle Relaxants}

Sedative-hypnotics and muscles relaxants are agents that may lead to the need for respiratory support in the ICU. Recently, alprazolam and carisoprodol have been noted to cause significant harm

Table 3-KCC for Liver Transplantation in Acetaminophen-Induced Acute Liver Failure*

\footnotetext{
List for transplantation if:

Arterial $\mathrm{pH}<7.3$ after adequate fluid resuscitation

List for transplantation if all three of the following occur within a 24-h period:

Creatinine $>3.4 \mathrm{mg} / \mathrm{dL}$

Prothrombin time $>100 \mathrm{~s}$ (international normalized ratio $>6.5$ )

Grade III or worse encephalopathy
}

*From Bernal et al. ${ }^{29}$ valuation Only.

to patients in overdoses. ${ }^{35,36}$ Alprazolam was specifically associated with an increased ICU length of stay when compared to other benzodiazepines. Flumazenil as a diagnostic agent in benzodiazepine overdose should be used cautiously, especially in those patients with chronic benzodiazepine use, epilepsy, or coingestion with medications that may increase the risk for seizures such as tricyclic antidepressants. ${ }^{37}$ Flumazenil is not indicated as a substitute for airway protection because its half-life is shorter than ingested benzodiazepines. ${ }^{38}$

\section{ANTIDEPRESSANTS}

Overdoses with cyclic antidepressants (CAs) are less common due to greater usage of selective serotonin reuptake inhibitors (SSRIs). ${ }^{39}$ Although there is insufficient evidence to support a particular therapy in CA overdose, the use of sodium bicarbonate to alkalinize blood to a $\mathrm{pH}$ of 7.45 to 7.55 is still considered the primary therapy to prevent and treat cardiac arrhythmias associated with CAs. ${ }^{40}$ Proposed criteria for initiating sodium bicarbonate have been variable (Table 4), but in general we recommend blood alkalinization with QRS > $120 \mathrm{~ms}$. Hypertonic saline solution may be a therapeutic option in refractory cases based on animal studies and limited clinical experience. The cardiotoxicity associated with CAs is due to sodium-channel blockade in the His-Purkinje and myocardial cells, and sodium helps to overcome this blockade. Additionally, CAs have $\alpha$-adrenergic blocking properties that may cause marked hypotension and $\alpha$-agonists such as norepinephrine are indicated to improve hypotension refractory to volume replacement. ${ }^{41,42}$

SSRI overdose is unlikely to cause significant harm unless large quantities are ingested acutely $(>75$ times the usual daily dose). Fatalities associated with SSRI overdose are almost always associated with co-ingestion of other substances. ${ }^{43}$ Serotonin syndrome (SS), which is a condition resulting from an excess of intrasynaptic serotonin, may occur with overdose or therapeutic use of SSRIs. This syndrome may also be associated with the use of serotonergic agents, including CAs, monoamine oxidase inhibi-

\section{Table 4-Potential Criteria for Use of Sodium} Bicarbonate in Antidepressant Overdose

Cardiac conduction delay, QRS $>100$ to $160 \mathrm{~ms}$

Wide complex tachyarrhythmia

Cardiac arrest

Right-bundle-branch block

$\mathrm{R}$ in $\mathrm{AVR} \geq 3 \mathrm{~mm}$

Refractory hypotension 

tors, and triptans, or co-administration of multiple serotonergic agents. ${ }^{44}$ Medications with monoamine oxidase inhibitor activity such as linezolid may precipitate the syndrome when administered concurrently with a serotonergic agent. ${ }^{45}$ Diagnosis requires recognition of symptoms that include mental status changes, autonomic instability (hyperthermia, heart rate and BP fluctuation, arrhythmias and diaphoresis), and neuromuscular abnormalities such as tremor, myoclonus, or hypertonicity. Symptoms of SS are usually noted to improve within $24 \mathrm{~h}$ after withdrawal of the offending agent(s). Severe manifestations of this syndrome may include hyperthermia and cardiorespiratory dysfunction necessitating aggressive interventions such as neuromuscular blockade and mechanical ventilatory support. Cyproheptadine, a drug with serotonin antagonist properties, has been advocated to treat SS in doses of 12 to $32 \mathrm{mg}$ daily; however, this recommendation is based on a few case reports. ${ }^{46-48}$

\section{ANTIPSYCHOTICS}

Patients presenting with antipsychotic overdose usually only require supportive care until clinical abnormalities including mental status changes, myotoxicity, and ECG abnormalities improve. The use of atypical antipsychotics, especially olanzapine, has been associated with the development of diabetes mellitus and diabetic ketoacidosis. The exact mechanism behind this relationship is unclear. Therapy requires addressing the metabolic abnormalities and consideration of a different antipsychotic such as risperidone, which is not significantly associated with the development of diabetes. ${ }^{49}$ The most significant complication associated with antipsychotic drugs is neuroleptic malignant syndrome (NMS). Although most commonly associated with haloperidol exposure, NMS is also reported with newer antipsychotic agents such as clozapine, olanzapine, and risperidone. Symptoms suggestive of this syndrome are very similar to the aforementioned SS and include mental status changes, autonomic instability, and skeletal muscle rigidity. Differentiating between the two syndromes is often difficult, and a thorough medication history is often necessary to delineate the specific etiology. ${ }^{50}$ As with SS, therapy requires cessation of the causal medication. Other medical therapies, including benzodiazepines, dopaminergic agents, and dantrolene, may be of benefit; however, the relative rarity of this syndrome precludes systematic evaluation of these interventions. Benzodiazepines appear to hasten recovery in milder cases and those with significant muscle rigidity. Use of amantadine and bromocriptine is associated with a de-

\section{valuation Only.}

crease in morbidity and mortality. ${ }^{51}$ Dantrolene has been recommended as a therapy for NMS, especially when significant hyperpyrexia and muscular rigidity are present, but a recent review ${ }^{52}$ did not reveal universal efficacy. Morbidity and mortality are often associated with autonomic instability and airway compromise, so appropriate monitoring and supportive care are essential.

The treatment of choice for significant lithium toxicity continues to be hemodialysis. The decision to institute hemodialysis therapy requires consideration of several factors, including risks of the procedure, duration of lithium exposure, severity of clinical manifestations, and serum lithium concentration (levels $>2.5$ $\mathrm{mmol} / \mathrm{L}$ in chronic exposure and $>4 \mathrm{mmol} / \mathrm{L}$ in acute exposure are potentially life threatening). Conventional hemodialysis is effective in rapidly reducing circulating lithium concentrations; however, intracellular lithium is less affected and subsequent transcellular equilibration leads to a rebound increase in lithium levels after hemodialysis. Thus, extended and repeated courses of hemodialysis may be necessary. The rapidly declining lithium levels during hemodialysis may be associated with adverse neurologic effects. The use of continuous renal replacement techniques avoids the rebound increase in lithium levels. ${ }^{53}$

\section{Cardiovascular Medications}

Significant overdoses with cardiovascular medications often require critical care support. All antihypertensives may cause harm, but overdoses with calcium-channel blockers (CCBs) and $\beta$-blockers result in the most severe hemodynamic abnormalities. As most $\beta$-blockers and CCBs used in clinical practice are long-acting formulations, delayed and continuous absorption can lead to prolonged clinical presentations. Whole-bowel irrigation may be considered in patients with delayed presentations. ${ }^{54}$ The dihidropyridine class of CCBs (eg, amlodipine and nimodipine) usually leads to significant hypotension without bradycardia, whereas the nondihidropyridine class of CCBs (eg, diltiazem and verapamil) leads most commonly to bradycardia and, in the most severe overdoses, cardiogenic shock and sinus arrest. Therapies for CCB overdose usually require volume resuscitation and vasopressors to maintain BP and heart rate. Vasopressors such as dopamine and norepinephrine are first-line agents, but hypotension unresponsive to these agents may respond to vasopressin. ${ }^{55}$ IV calcium salts are also often used in supraphysiologic doses, and care must be taken to avoid extravasation during IV administration. Ionized calcium levels should be monitored when using high doses of calcium. IV glucagon is not as widely 
accepted for CCB toxicity as it is for $\beta$-blocker toxicity, but a review ${ }^{56}$ of animal studies suggests a possible beneficial effect in both toxicities. A hyperinsulinemic euglycemia protocol requiring insulin infusion while maintaining acceptable serum glucose levels by exogenous glucose administration is another therapeutic choice in severe CCB overdose. ${ }^{57,58}$ To date, evidence supporting this therapy is based on case reports and one case series that demonstrates improvement in BP and metabolic acidosis. ${ }^{59}$ The benefit afforded by insulin appears to be due to increased cardiac carbohydrate metabolism efficiency and direct inotropic effects of insulin. ${ }^{54,60}$ Insulin infusion rates of 0.5 to $1 \mathrm{U} / \mathrm{kg} / \mathrm{h}$ or higher have been reported, and close monitoring for prevention of hypoglycemia and hypokalemia is imperative. Severe CCB toxicity unresponsive to therapies mentioned above may require cardiac pacing and other advanced therapies such as intra-aortic balloon pump or extracorporeal membrane oxygenation. ${ }^{61}$

$\beta$-Blocker toxicity is still most commonly treated by administering high-dose glucagon therapy. A glucagon bolus of 5 to $10 \mathrm{mg}(150 \mu \mathrm{g} / \mathrm{kg})$ over 1 to $2 \mathrm{~min}$ is frequently used in this setting. Clinical effect (increased heart rate or BP) is usually noted within a few minutes; however, as glucagon has a short duration of action, a continuous infusion of 2 to 10 $\mathrm{mg} / \mathrm{h}$ is usually necessary. ${ }^{58}$ Nausea and vomiting can be noted as a side effect of high-dose glucagon therapy. ${ }^{62}$ The hyperinsulinemic euglycemia protocol, as discussed above, may also have some benefit in $\beta$-blocker toxicity. ${ }^{54,59}$

\section{AlCOHOLS}

Toxicity due to ethylene glycol and methanol is still encountered in the ICU. Early diagnosis by history and appropriate laboratory evaluation is imperative, as is early therapy with alcohol dehydrogenase inhibitors such as fomepizole and ethanol. Fomepizole is easier to administer, does not require monitoring of levels, and does not produce sedation; however, fomepizole is significantly more expensive than ethanol. Ethanol can be administered orally or IV but requires monitoring of blood levels, and patients often require intubation due to sedative effects. Both therapies require adjustments of increased dosages with dialysis. The presence of an osmolar gap without an anion-gap metabolic acidosis suggests an early presentation after ingestion, before metabolism of the alcohol to acids or the concomitant presence of significant ethanol. In these cases, therapy with fomepizole alone may be considered, and hemodialysis may be avoided. However, close monitoring of acid-base and renal status is para- mount to ensure appropriate response to therapy. ${ }^{63}$ If an anion-gap metabolic acidosis is present without a significant osmolar gap, the alcohol has likely been metabolized to acids, and hemodialysis is necessary to remove the toxic metabolites. The utility of urine fluorescence to aid in the diagnosis of suspected ethylene glycol ingestion has been questioned. ${ }^{64}$

Another alcohol toxicity that may be encountered in ICU patients is propylene glycol toxicity. This agent is usually associated with prolonged, high-dose IV infusions of lorazepam or diazepam as propylene glycol is the medication solvent. Significant lactic acidosis, hypotension, and multisystem organ dysfunction have been reported that responds rapidly to cessation of the offending medication. ${ }^{65}$ Changing the benzodiazepine to a similar agent such as midazolam is usually required to minimize the risk of benzodiazepine withdrawal. Propylene glycol can also be found in commercially available antifreeze and de-icing solutions, and at least one case has been reported of ingestion leading to propylene glycol toxicity. ${ }^{66}$

Recently reported cases ${ }^{67,68}$ of hand sanitizer ingestion in a prison and a hospital may herald a new trend, as hand sanitizer use has become ubiquitous. Most hand sanitizers dispense ethanol or isopropanol-based solutions. Health-care providers need to consider the possibility of misuse of these agents resulting in toxicity.

\section{ILLICIT DRUGS}

Toxicity associated with illicit drugs, such as cocaine, amphetamines, phencyclidine, heroin, and $\gamma$-hydroxybutyrate, is commonly encountered in critical care units. Treatment is largely supportive, and recognition of toxicity allows focused care aimed at treating and preventing complications. Unfortunately, there have been no significant advances in treatment of illicit drug toxicity in critical care. A recently published review ${ }^{69}$ of this topic summarizes relevant information.

\section{CARbon Monoxide}

Carbon monoxide poisoning is likely the most common cause of fatal poisoning worldwide. ${ }^{70}$ Therapy for carbon monoxide poisoning centers on providing supplemental $100 \%$ oxygen and considering use of hyperbaric oxygen. The indications for use of hyperbaric oxygen continue to be debated, but therapy may be considered for patients with significant carbon monoxide poisoning. Consultation with a hyperbaric oxygen specialist should be performed to assess the need for and specifics associated with the therapy. ${ }^{71-73}$ 


\section{MethemogLOBinemia}

For Evaluation Only.

occurs infrequently in the United States. The use of supportive care, including early mechanical ventilation and pharmacotherapy with atropine, is well established. ${ }^{1}$ Oximes such as pralidoxime and obidoxime are frequently utilized to reverse muscle weakness, but significant clinical evidence to support use of oximes in organophosphate toxicity is lacking. ${ }^{80,81}$ Fresh frozen plasma may also be of benefit in treatment, possibly by increasing plasma cholinesterase levels. $^{82}$ A study ${ }^{83}$ found Glasgow coma scale score $<6$ and corrected QT $>610 \mathrm{~ms}$ to be good predictors of respiratory failure in patients presenting with organophosphate poisoning. This data are of value to medical support systems in developing countries with limited resources.

\section{SUMMARY}

The management of toxicity in critical care requires significant effort by the clinician to recognize and rapidly evaluate patients in order that focused therapies may be instituted. Incorporation of available scientific data and evidence along with clinical judgment is necessary to determine the best possible therapeutic course. As new agents are introduced into clinical practice or illicit use, it is vitally important that clinicians maintain knowledge of toxic effects and their management. Resources such as toxicology specialists and Poison Control Centers should be consulted for needed assistance. In the United States, the nationwide Poison Control Center phone number is 1-800-222-1222. An additional resource available by subscription is the Web-based POISINDEX® system. ${ }^{84}$

\section{REFERENCES}

1 Betten DP, Vohra RB, Cook MD, et al. Antidote use in the critically ill poisoned patient. J Intensive Care Med 2006; 21:255-277

2 Mokhlesi B, Leikin JB, Murray P, et al. Adult toxicology in critical care: part II: specific poisonings. Chest 2003; 123: 897-922

3 Mokhlesi B, Leiken JB, Murray P, et al. Adult toxicology in critical care: part I: general approach to the intoxicated patient. Chest 2003; 123:577-592

4 Zimmerman JL. Poisonings and overdoses in the intensive care unit: general and specific management issues. Crit Care Med 2003; 31:2794-2801

5 von Mach MA, Weber C, Meyer MR, et al. Comparison of urinary on-site immunoassay screening and gas chromatographymass spectrometry results of 111 patients with suspected poisoning presenting at an emergency department. Ther Drug Monit 2007; 29:27-39

6 Montague RE, Grace RF, Lewis JH, et al. Urine drug screens in overdose patients do not contribute to immediate clinical management. Ther Drug Monit 2001; 23:47-50

7 Chyka PA, Seger D, Krenzelok EP, et al. Position paper:
Cholinergic toxicity caused by organophosphates is encountered commonly in developing countries but 
single-dose activated charcoal. Clin Toxicol (Phila) 2005; 43:61-87

8 Position paper: cathartics. J Toxicol Clin Toxicol 2004; 42: 243-253

9 Position paper: ipecac syrup. J Toxicol Clin Toxicol 2004; 42:133-143

10 Vale JA, Kulig K. Position paper: gastric lavage. J Toxicol Clin Toxicol 2004; 42:933-943

11 Position paper: whole bowel irrigation: J Toxicol Clin Toxicol 2004; 42:843-854

12 Proudfoot AT, Krenzelok EP, Vale JA. Position paper on urine alkalinization. J Toxicol Clin Toxicol 2004; 42:1-26

13 Position statement and practice guidelines on the use of multi-dose activated charcoal in the treatment of acute poisoning. American Academy of Clinical Toxicology; European Association of Poisons Centres and Clinical Toxicologists. J Toxicol Clin Toxicol 1999; 37:731-751

14 Goldfarb DS, Matalon D. Principles and techniques applied to enhance elimination. In: Goldfrank LR, Flomenbaum NE, Lewin NA, et al, eds. Goldfrank's toxicologic emergencies, 8th ed. New York, NY: McGraw Hill, 2006

15 Goodman JW, Goldfarb DS. The role of continuous renal replacement therapy in the treatment of poisoning. Semin Dial 2006; 19:402-407

16 Lai MW, Klein-Schwartz W, Rodgers GC, et al. 2005 annual report of the American Association of Poison Control Centers' national poisoning and exposure database. Clin Toxicol (Phila) 2006; 44:803-932

17 Rumack BH, Matthew H. Acetaminophen poisoning and toxicity. Pediatrics 1975; 55:871-876

18 Bond GR, Hite LK. Population-based incidence and outcome of acetaminophen poisoning by type of ingestion. Acad Emerg Med 1999; 6:1115-1120

19 Cetaruk EW, Dart RC, Hurlbut KM, et al. Tylenol extended relief overdose. Ann Emerg Med 1997; 30:104-108

20 Brok J, Buckley N, Gluud C. Interventions for paracetamol (acetaminophen) overdose. Cochrane Database Syst Rev 2006; 2:CD003328

21 Kanter MZ. Comparison of oral and i.v. acetylcysteine in the treatment of acetaminophen poisoning. Am J Health Syst Pharm 2006; 63:1821-1827

22 Kerr F, Dawson A, Whyte IM, et al. The Australasian Clinical Toxicology Investigators Collaboration randomized trial of different loading infusion rates of $\mathrm{N}$-acetylcysteine. Ann Emerg Med 2005; 45:402-408

23 Goldfrank LR, Flomenbaum NE, Lewin NA, et al, eds. Goldfrank's toxicologic emergencies, 8th ed. New York, NY: McGraw Hill, 2006

24 Daly FF, O’Malley GF, Heard K, et al. Prospective evaluation of repeated supratherapeutic acetaminophen (paracetamol) ingestion. Ann Emerg Med 2004; 44:393-398

25 Buckley NA, Whyte IM, O'Connell DL, et al. Activated charcoal reduces the need for $\mathrm{N}$-acetylcysteine treatment after acetaminophen (paracetamol) overdose. J Toxicol Clin Toxicol 1999; 37:753-757

26 Spiller HA, Sawyer TS. Impact of activated charcoal after acute acetaminophen overdoses treated with $\mathrm{N}$-acetylcysteine. J Emerg Med 2007; 33:141-144

27 Spiller HA, Krenzelok EP, Grande GA, et al. A prospective evaluation of the effect of activated charcoal before oral $\mathrm{N}$-acetylcysteine in acetaminophen overdose. Ann Emerg Med 1994; 23:519-523

28 Rowden AK, Norvell J, Eldridge DL, et al. Updates on acetaminophen toxicity. Med Clin North Am 2005; 89:1145-1159

29 Bernal W, Wendon J, Rela M, et al. Use and outcome of liver transplantation in acetaminophen-induced acute liver failure. Hepatology 1998; 27:1050-1055
30 van Dorp E, Yassen A, Sarton E, et al. Naloxone reversal of buprenorphine-induced respiratory depression. Anesthesiology $2006 ; 105: 51-57$

31 Tjaderborn M, Jonsson AK, Hagg S, et al. Fatal unintentional intoxications with tramadol during 1995-2005. Forensic Sci Int 2007: 173:107-111

32 Jovanovic-Cupic V, Martinovic Z, Nesic N. Seizures associated with intoxication and abuse of tramadol. Clin Toxicol (Phila) 2006; 44:143-146

33 Martin TL, Woodall KL, McLellan BA. Fentanyl-related deaths in Ontario, Canada: toxicological findings and circumstances of death in 112 cases (2002-2004). J Anal Toxicol 2006; 30:603-610

34 Kuhlman JJ Jr, McCaulley R, Valouch TJ, et al. Fentanyl use, misuse, and abuse: a summary of 23 postmortem cases. J Anal Toxicol 2003; 27:499-504

35 Hoiseth G, Bramness JG, Christophersen AS, et al. Carisoprodol intoxications: a retrospective study of forensic autopsy material from 1992-2003. Int J Legal Med 2006

36 Isbister GK, O'Regan L, Sibbritt D, et al. Alprazolam is relatively more toxic than other benzodiazepines in overdose. Br J Clin Pharmacol 2004; 58:88-95

37 Ngo AS, Anthony CR, Samuel M, et al. Should a benzodiazepine antagonist be used in unconscious patients presenting to the emergency department? Resuscitation 2007; 74:27-37

38 Seger DL. Flumazenil: treatment or toxin. J Toxicol Clin Toxicol 2004; 42:209-216

39 McKenzie MS, McFarland BH. Trends in antidepressant overdoses. Pharmacoepidemiol Drug Saf 2007; 16:513-523

40 Bradberry SM, Thanacoody HK, Watt BE, et al. Management of the cardiovascular complications of tricyclic antidepressant poisoning: role of sodium bicarbonate. Toxicol Rev 2005; 24:195-204

41 McCabe JL, Cobaugh DJ, Menegazzi JJ, et al. Experimental tricyclic antidepressant toxicity: a randomized, controlled comparison of hypertonic saline solution, sodium bicarbonate, and hyperventilation. Ann Emerg Med 1998; 32:329-333

42 McKinney PE, Rasmussen R. Reversal of severe tricyclic antidepressant-induced cardiotoxicity with intravenous hypertonic saline solution. Ann Emerg Med 2003; 42:20-24

43 Barbey JT, Roose SP. SSRI safety in overdose. J Clin Psychiatry 1998; 59(suppl 15):42-48

44 Evans CE, Sebastian J. Serotonin syndrome. Emerg Med J: 2007; 24:e20

45 Taylor JJ, Wilson JW, Estes LL. Linezolid and serotonergic drug interactions: a retrospective survey. Clin Infect Dis 2006; 43:180-187

46 Boyer EW, Shannon M. The serotonin syndrome. N Engl J Med 2005; 352:1112-1120

47 Paruchuri P, Godkar D, Anandacoomarswamy D, et al. Rare case of serotonin syndrome with therapeutic doses of paroxetine. Am J Ther 2006; 13:550-552

48 Graudins A, Stearman A, Chan B. Treatment of the serotonin syndrome with cyproheptadine. J Emerg Med 1998; 16:615619

49 Varma MK, Connolly K, Fulton B. Life-threatening hyperglycemia and acidosis related to olanzapine: a case report and review of the literature. J Intensive Care Med 2007; 22:52-55

50 Kaufman KR, Levitt MJ, Schiltz JF, et al. Neuroleptic malignant syndrome and serotonin syndrome in the critical care setting: case analysis. Ann Clin Psychiatry 2006; 18:201204

51 Strawn JR, Keck PE Jr, Caroff SN. Neuroleptic malignant syndrome. Am J Psychiatry 2007; 164:870-876

52 Reulbach U, Dutsch C, Biermann T, et al. Managing an effective treatment for neuroleptic malignant syndrome. Crit Care 2007; 11:R4 
53 Waring WS. Management of lithium toxicity. Toxicol Rev 2006; 25:221-230

54 Shepherd G. Treatment of poisoning caused by beta-adrenergic and calcium-channel blockers. Am J Health Syst Pharm 2006; 63:1828-1835

55 Kanagarajan K, Marraffa JM, Bouchard NC, et al. The use of vasopressin in the setting of recalcitrant hypotension due to calcium channel blocker overdose. Clin Toxicol (Phila) 2007; 45:56-59

56 Bailey B. Glucagon in $\beta$-blocker and calcium channel blocker overdoses: a systematic review. J Toxicol Clin Toxicol 2003; 41:595-602

57 Harris NS. Case records of the Massachusetts General Hospital: case 24-2006; a 40-year-old woman with hypotension after an overdose of amlodipine. N Engl J Med 2006; 355:602-611

58 DeWitt CR, Waksman JC. Pharmacology, pathophysiology and management of calcium channel blocker and $\beta$-blocker toxicity. Toxicol Rev 2004; 23:223-238

59 Yuan TH, Kerns WP, Tomaszewski CA, et al. Insulin-glucose as adjunctive therapy for severe calcium channel antagonist poisoning. J Toxicol Clin Toxicol 1999; 37:463-474

60 Megarbane B, Karyo S, Baud FJ. The role of insulin and glucose (hyperinsulinaemia/euglycaemia) therapy in acute calcium channel antagonist and $\beta$-blocker poisoning. Toxicol Rev 2004; 23:215-222

61 Newton CR, Delgado JH, Gomez HF. Calcium and beta receptor antagonist overdose: a review and update of pharmacological principles and management. Semin Respir Crit Care Med 2002; 23:19-25

62 White CM. A review of potential cardiovascular uses of intravenous glucagon administration. J Clin Pharmacol 1999; 39:442-447

63 Megarbane B, Borron SW, Baud FJ. Current recommendations for treatment of severe toxic alcohol poisonings. Intensive Care Med 2005; 31:189-195

64 Parsa T, Cunningham SJ, Wall SP, et al. The usefulness of urine fluorescence for suspected antifreeze ingestion in children. Am J Emerg Med 2005; 23:787-792

65 Wilson KC, Reardon C, Theodore AC, et al. Propylene glycol toxicity: a severe iatrogenic illness in ICU patients receiving IV benzodiazepines; a case series and prospective, observational pilot study. Chest 2005; 128:1674-1681

66 Brooks DE, Wallace KL. Acute propylene glycol ingestion. J Toxicol Clin Toxicol 2002; 40:513-516

67 Emadi A, Coberly L. Intoxication of a hospitalized patient with an isopropanol-based hand sanitizer. N Engl J Med 2007; 356:530-531

68 Doyon S, Welsh C. Intoxication of a prison inmate with an ethyl alcohol-based hand sanitizer. N Engl J Med 2007; 356:529-530
69 Mokhlesi B, Ǵ, 1536

70 Raub JA, Mathieu-Nolf M, Hampson NB, et al. Carbon monoxide poisoning-a public health perspective. Toxicology 2000; 145:1-14

71 Juurlink DN, Buckley NA, Stanbrook MB, et al. Hyperbaric oxygen for carbon monoxide poisoning. Cochrane Database Syst Rev 2005; 1:CD002041

72 Stoller KP. Hyperbaric oxygen and carbon monoxide poisoning: a critical review. Neurol Res 2007; 29:146-155

73 Weaver LK, Hopkins RO, Chan KJ, et al. Hyperbaric oxygen for acute carbon monoxide poisoning. N Engl J Med 2002; 347:1057-1067

74 Novaro GM, Aronow HD, Militello MA, et al. Benzocaineinduced methemoglobinemia: experience from a high-volume transesophageal echocardiography laboratory. J Am Soc Echocardiogr 2003; 16:170-175

75 Moore TJ, Walsh CS, Cohen MR. Reported adverse event cases of methemoglobinemia associated with benzocaine products. Arch Intern Med 2004; 164:1192-1196

76 U.S. Food and Drug Administration Public Health Advisory. http:// www.fda.gov/cder/drug/advisory/benzocaine.htm. Accessed March 5, 2008

77 Fudickar A, Bein B, Tonner PH. Propofol infusion syndrome in anaesthesia and intensive care medicine. Curr Opin Anaesthesiol 2006; 19:404-410

78 Liolios A, Guerit JM, Scholtes JL, et al. Propofol infusion syndrome associated with short-term large-dose infusion during surgical anesthesia in an adult. Anesth Analg 2005; 100:1804-1806

79 Kam PC, Cardone D. Propofol infusion syndrome. Anaesthesia 2007; 62:690-701

80 Peter JV, Moran JL, Graham P. Oxime therapy and outcomes in human organophosphate poisoning: an evaluation using meta-analytic techniques. Crit Care Med 2006; 34:502-510

81 Buckley NA, Eddleston M, Szinicz L. Oximes for acute organophosphate pesticide poisoning. Cochrane Database Syst Rev 2005; 1:CD005085

82 Guven M, Sungur M, Eser B, et al. The effects of fresh frozen plasma on cholinesterase levels and outcomes in patients with organophosphate poisoning. J Toxicol Clin Toxicol 2004; 42:617-623

83 Grmec S, Mally S, Klemen P. Glasgow coma scale score and QTc interval in the prognosis of organophosphate poisoning. Acad Emerg Med 2004; 11:925-930

84 Thomson Healthcare and Compliance. POISINDEX system. Available at: http://www.micromedex.com/products/poisindex/. Accessed March 5, 2008 
Toxicology in the Critical Care Unit

Philip M. Alapat and Janice L. Zimmerman

Chest 2008;133;1006-1013

DOI 10.1378/chest.07-1840

This information is current as of May 8, 2008

\section{Updated Information \\ \& Services}

References

Permissions \& Licensing

Reprints

Email alerting service

Images in PowerPoint format Figures that appear in CHEST articles can be

downloaded for teaching purposes in PowerPoint slide format. See any online article figure for directions.

Updated information and services, including high-resolution figures, can be found at:

http://chestjournal.org/cgi/content/full/133/4/1006

This article cites 79 articles, 18 of which you can access for free at:

http://chestjournal.org/cgi/content/full/133/4/1006\#BIBL

Information about reproducing this article in parts

(figures, tables) or in its entirety can be found online at:

http://chestjournal.org/misc/reprints.shtml

Information about ordering reprints can be found online: http://chestjournal.org/misc/reprints.shtml

Receive free email alerts when new articles cite this article sign up in the box at the top right corner of the online article.

A M E R I C A N C O L L E G E O F

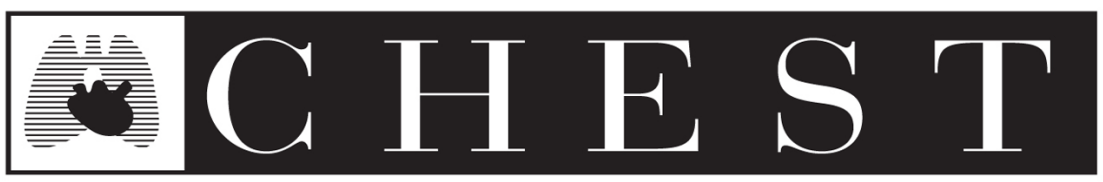

$\begin{array}{llllllllll}\mathrm{P} & \mathrm{H} & \mathrm{Y} & \mathrm{S} & \mathrm{I} & \mathrm{C} & \mathrm{I} & \mathrm{A} & \mathrm{N} & \mathrm{S}\end{array}$ 